\title{
Pigmentação dentária por sulfato ferroso: relato de caso
}

\author{
Dental pigmentation by ferrous sulfate: case report
}

Pigmentación dental por sulfato ferroso: relato de caso

\begin{abstract}
Katherine Elice Paes Leão Coelho ${ }^{1 *}$, Bárbara Geovanna Silva Souza ${ }^{1}$, Cristiano Santana Bentes Júnior ${ }^{1}$, Carolina Vitória de Souza Martins ${ }^{1}$, Amanda Cruz Rocha ${ }^{1}$, Gabriela Gonçalves Lobo ${ }^{1}$, Desireé da Silva Duarte ${ }^{1}$, Nadja Miranda Bemerguy ${ }^{1}$, Nayara Cardoso Santos ${ }^{1}$, Luís Paulo Almeida Campos ${ }^{1}$, Jéssica Paiva de Sousa ${ }^{1}$, Martha Caroline Auzier Quaresma $^{1}$, Thaís Freitas Silva ${ }^{1}$, Beatriz Freitas da Costa ${ }^{1}$, Jorge Sá Elias Nogueira ${ }^{1}$.
\end{abstract}

\section{RESUMO}

Objetivo: relatar um caso clínico de pigmentação dentária por sulfato ferroso. Detalhamentos de Caso: Paciente, 8 anos, chegou acompanhado de seus responsáveis à Unidade Odontológica Infantil do CESUPA queixando-se de manchas dentárias escurecidas. $\mathrm{Na}$ anamnese, os responsáveis relataram que o paciente realizou um tratamento com sulfato ferroso para anemia ferropriva. No exame clínico, foi constatado a presença de dentição mista e uma boa higiene oral; entretanto, verificou-se pigmentações enegrecidas a nível de esmalte dentário. Logo, o tratamento odontológico foi dividido em duas sessões; sendo a primeira sessão realizada com profilaxia por meio de Pasta Profilática, Pedra Pomes e escova de Robson; e a segunda sessão, realizada com jato de bicarbonato e curetas de Gracey. O paciente ficou em proservação em um período de 4 meses e quando regressou, notou-se a recidiva das pigmentações; devido a retomada do tratamento; impossibilitando a intervenção bucal. Após 1 mês, tendo terminado sua intervenção médica, o paciente retornou para o tratamento odontológico para a remoção das pigmentações, utilizando-se do mesmo método anterior, sendo necessário apenas uma sessão; visto a redução da intensidade das pigmentações. Conclusão: É primordial a remoção das manchas tanto para o não comprometimento do periodonto marginal, quanto para não implicação na estética.

Palavras-chave: Sulfato Ferroso, Anemia Ferropriva, Esmalte Dentário.

\begin{abstract}
Objective: to report a clinical case of dental pigmentation by ferrous sulfate. Case Detail: Patient, 8 years old, came with his parents to the CESUPA Children's Dentistry Unit complaining about dental black stains. In the anamnesis, those in charge reported that the patient underwent treatment with ferrous sulfate for iron deficiency anemia. In the clinical examination, the presence of mixed dentition and good oral hygiene was verified; however, blackened pigmentations at the level of tooth enamel were observed. Therefore, dental treatment was divided into two sessions; being the first session performed with prophylaxis through Prophylactic Pastes, Pumice Stone and Robson brush; and the second session, performed with bicarbonate jet and Gracey's curettes. The patient was undergoing a period of 4 months, and when he returned, the recurrence of pigmentation was noted; due to resumption of treatment; making oral intervention impossible. After 1 month, having finished his medical intervention, the patient returned to the dental treatment for the removal of the pigmentations, using the same previous method, requiring only one session; seen the reduction of pigment intensity. Conclusion: It is essential to remove the stains both for non-impairment of the marginal periodontium and for non-involvement in the aesthetics.
\end{abstract}

Key words: Ferrous Sulfate, Iron-Deficiency, Dental Enamel.

${ }^{1}$ Centro Universitário do Pará (CESUPA), Belém-PA. *E-mail: kat_leao@hotmail.com

SUBMETIDO EM: 4/2019

ACEITO EM: 5/2019

PUBLICADO EM: 7/2019

REAS/EJCH | Vol. Sup.27 | e832 | DOI: https://doi.org/10.25248/reas.e832.2019 Página 1 de $\mathbf{7}$ 


\section{RESUMEN}

Objetivo: relatar un caso clínico de pigmentación dental por sulfato ferroso. Detalle de Caso: Paciente, 8 años, llegó acompañado de sus responsables a la Unidad Odontológica Infantil del CESUPA quejándose de manchas dentales oscurecidas. En la anamnesis, los responsables relataron que el paciente realizó un tratamiento con sulfato ferroso para anemia ferropriva. En el examen clínico, se constató la presencia de dentición mixta y una buena higiene oral; sin embargo, se verificaron pigmentaciones ennegrecidas a nivel de esmalte dental. Por lo tanto, el tratamiento odontológico se dividió en dos sesiones; siendo la primera sesión realizada con profilaxis por medio de Pasta Profiláctica, Piedra Pomes y cepillo de Robson; y la segunda sesión, realizada con chorro de bicarbonato y curetas de Gracey. El paciente se quedó en proservación en un período de 4 meses y cuando regresó, se notó la recidiva de las pigmentaciones; debido a la reanudación del tratamiento; que imposibilitan la intervención oral. Después de 1 mes, habiendo terminado su intervención médica, el paciente retornó al tratamiento odontológico para la remoción de las pigmentaciones, utilizando el mismo método anterior, siendo necesario sólo una sesión; ya que la reducción de la intensidad de las pigmentaciones. Conclusión: Es primordial la remoción de las manchas tanto para el no comprometimiento del periodonto marginal, cuanto para no implicación en la estética.

Palabras clave: Sulfato Ferroso, Anemia Ferropénica, Esmalte Dental.

\section{INTRODUÇÃO}

As pigmentações negras de esmalte dentário se devem à coloração extrínseca, consequentemente associam-se com problemas estéticos, sendo que essas manchas podem estar associadas à utilização de sulfato ferroso para o tratamento de anemia por deficiência de ferro; portanto, é possível observar a presença de pigmentações negras nos dentes decíduos e nos primeiros molares permanentes (BRANCO CMCC, et al., 2016).

Segundo a Organização Mundial da Saúde (OMS) 2015, a anemia caracteriza-se como uma condição na qual a concentração sanguínea de hemoglobina se encontra abaixo dos valores esperados, tornando-se insuficiente para atender as necessidades fisiológicas exigidas de acordo com idade, sexo, gestação e altitude.

A deficiência de ferro é um importante fator para o desenvolvimento da anemia ferropriva, uma vez que essa substância caracteriza-se como um micronutriente que atua principalmente na síntese de glóbulos vermelhos do sangue, sendo necessário para a obtenção de uma adequada função eritropoiética; além de participar da respiração (transporte de oxigênio no organismo), produção de energia, síntese de DNA e proliferação celular (CAMASCHELLA C, 2015).

Nesse contexto, podem-se observar pigmentações enegrecidas em crianças que fazem suplementação medicamentosa com sulfato ferroso, desse modo, essas manchas aparecem praticamente em quase todos os dentes molares na região cervical. Vale ressaltar que essas pigmentações não se caracterizam como falta de higiene bucal e tendem reduzir á medida que a criança cresce (LANGSTAFF RJ, 2014).

Sendo mais frequentes na dentição decídua, essas manchas extrínsecas enegrecidas apresentam-se com uma intensidade variável, as quais são resultantes de depósitos de sais ferrosos procedentes de dieta ou suplementação alimentar que são metabolizados por bactérias cromogênicas presentes na flora bucal, podendo também estar correlacionadas a derivados de uma composição de saliva modificada com elevação de substâncias como cálcio, fósforo, cobre, sódio e redução de proteínas (SILVA ME, 2016).

Uma pesquisa realizada em dois grupos de crianças, com e sem pigmentações enegrecidas nos dentes, revelaram por meio da coleta da placa dental que o ferro estava presente nas duas amostras, entretanto, verificou-se uma concentração significativamente maior da substância na placa bacteriana dos dentes com manchas escuras. Sendo assim, para averiguar a correlação da etiologia de bactéria com essas 
pigmentações, os genes funcionais das bactérias referentes à placa dental com manchas escuras foram acessados, verificando-se uma associação dos genes com o ferro. Logo, essas descobertas forneceram pistas sobre a pesquisa da etiologia da mancha negra, que perturbou milhões de crianças e também revelou a associação entre a via metabólica da microbiota e o fenômeno oral (ZHANG F, et al., 2017)

Nessa linha de raciocínio, sugere-se que a pigmentação negra ocorre pela ação das bactérias cromogênicas, como Prevotella melaninogênica e do ferro presente na saliva e no fluido gengival (COSTA MT, et al., 2012), e outros agentes microbiológicos, como Porphyromonas gingivalis e Actinomyces naes/und baixa contagem de Fusobacterium nucleatum e Lactobacillus sp. (HEINRICH-WELTZIEN R, et al.,2014)

Dito isso, a presente pesquisa pretende averiguar por meio de um relato de caso a correlação das pigmentações dentárias enegrecidas em uma criança com anemia ferropriva, a qual estava realizando suplementação férrica; além de estudar as terapias indicadas nessa situação.

\section{DETALHADAMENTO DO CASO}

Paciente do sexo masculino, 8 anos, chegou acompanhado do seu responsável à Unidade Odontológica Infantil do CESUPA queixando-se de manchas dentárias escurecidas. $\mathrm{Na}$ anamnese, os responsáveis relataram que o paciente realizou um tratamento para anemia ferropriva com o medicamento Vitawin $2^{\circledR}$ (SANOFI, SP-BRASIL), tomando $2,5 \mathrm{ml}$ no jantar e no almoço, durante o período de três meses, e o mesmo já havia sido terminado. No exame clínico, foi constatado que o paciente apresentava uma característica de palidez, com um crescimento normal estava na dentição Inter transitória e apresentava boa higiene oral. Entretanto, verificaram-se manchas enegrecidas em nível de esmalte dentário na palatina dos dentes 16, 55, 12, 11, 21,65, 26 (Figura 1A); na área cervical vestibular dos dentes 55, 16,46 (Figura 1B) e na área cervical da palatina dos dentes 31, 41,42 (Figura 1C).

Figura 1 - (A) Pigmentações enegrecidas na palatina dos dentes 11,12, 21, 55,16, 65, 26. (B) Mancha na área cervical vestibular do dente 46. (C) Pigmentações por sulfato ferroso na área cervical da palatina $31,41,42$.

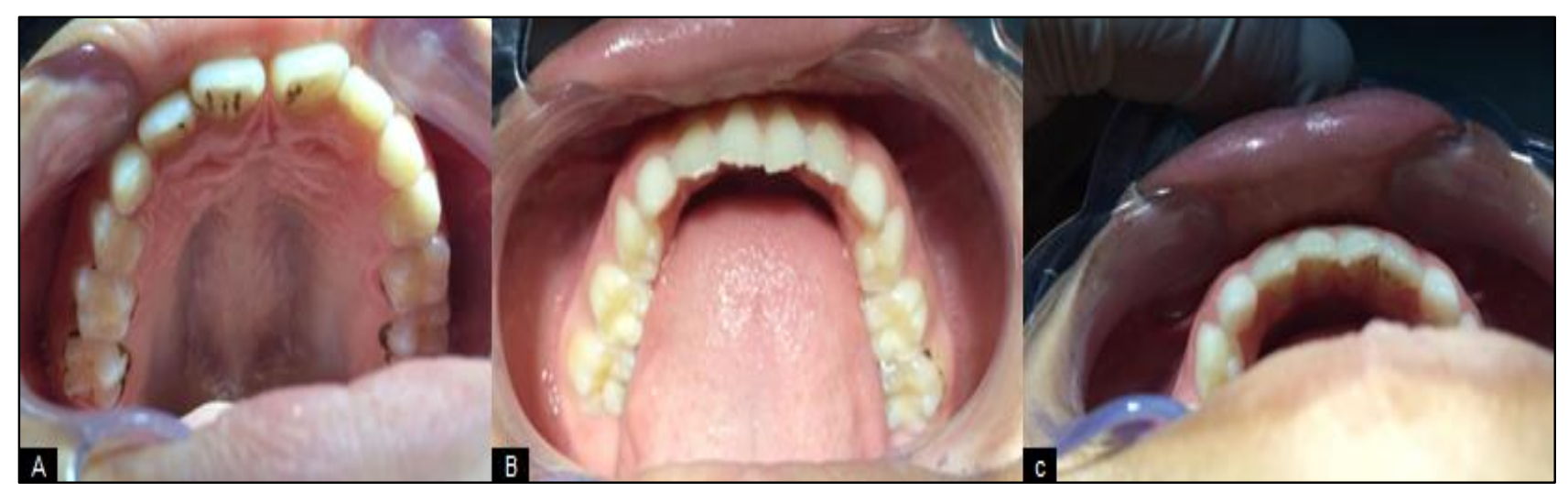

Fonte: Dados do trabalho, 2019.

Após um intenso estudo sobre o caso, com a correlação entre as pigmentações dentárias enegrecidas com medicações por sulfato ferroso, o tratamento de escolha foi dividido em duas sessões. Na primeira sessão realizou-se uma profilaxia com Pasta Profilática Herjos Tutti-Frutti (COLTENEE - BRASIL), Pedra Pomes Asfer (BRASIL) e escova de Robson (Microdont $\AA$, SP - BRASIL) para remoção das manchas enegrecidas mais proeminentes e aplicação de flúor neutro Flugel (DFL - BRASIL). Após duas semanas o paciente retornou à clínica para segunda sessão, sendo que nessa etapa foi utilizado o jato de bicarbonato e curetas de Gracey para remoção de manchas enegrecidas nas áreas de difícil acesso. 
Figura 2 - Resultado após realização do tratamento, com remoção completa das pigmentações enegrecidas.

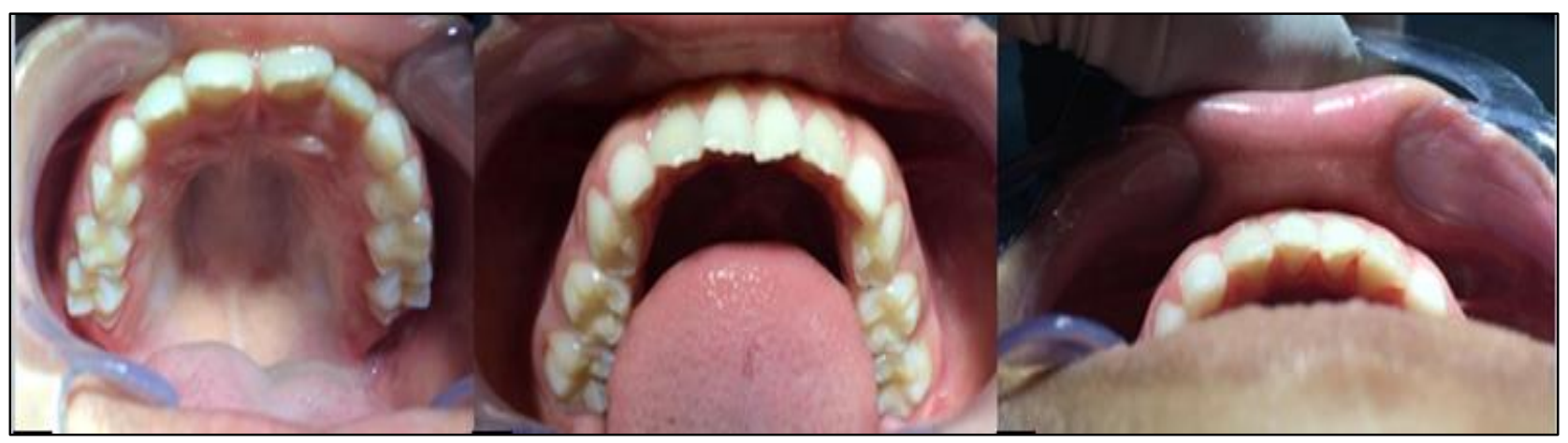

Fonte: Dados do trabalho, 2019.

Após a finalização do tratamento observou-se a remoção completa das manchas (Figura 2) e o paciente foi liberado; entretanto, continuou-se fazendo a preservação para averiguar se haveria ou não reincidência das pigmentações. Desse modo, após 4 meses o paciente retornou para uma nova avaliação e relatou que necessitou realizar um novo tratamento para anemia ferropriva; dessa vez com o medicamento DayVit (ACHÉBRASIL), ingerindo $5 \mathrm{ml}$ uma vez ao dia; durante os 4 meses. O responsável do paciente ainda relatou que 0 mesmo ainda faria novo acompanhamento médico para verificação da melhora do quadro de anemia e acompanhamento de nutricionista para uma alimentação adequada.

Ao exame clínico verificou-se boa higiene bucal e reaparecimento das pigmentações escuras; porém verificou-se uma pequena redução coloração das manchas enegrecidas, sendo apenas observadas nas superfícies palatinas dos dentes 16, 55, 65, 26, 36, 31, 32, 41, 42, 46 (Figuras 3A e 3C) e no vestibular dos dentes 16, 85,46 (Figura 3B). Visto que o paciente ainda estava no término de sua suplementação ferropriva medicamentosa, não foi possível realizar a sessão de profilaxia, diante da possibilidade de reaparecimento mediato; logo, o mesmo foi remarcado e continuou-se fazendo a proservação.

Figura 3 - (A) Manchas enegrecidas nas superfícies palatinas dos dentes 16, 55, 65, 26. (B) Pigmentações por sulfato ferroso no vestibular dos dentes $16,85,46$. (C) Pigmentações na palatina dos dentes $31,32,41$, 42.

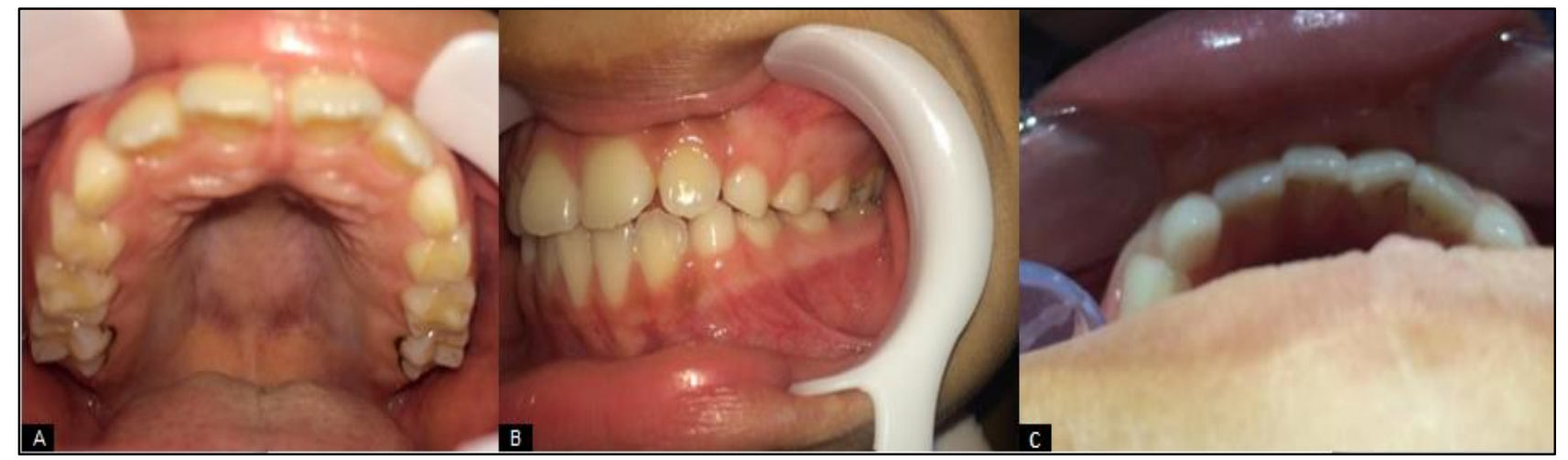

Fonte: Dados do trabalho, 2019.

Após 1 mês o paciente retornou, acompanhado de seu responsável, à Unidade Odontológica Infantil do CESUPA, sendo que foi relatado o término da ingestão do medicamento de suplementação férrica e uma melhora significativa da anemia ferropriva. Somado a isso, constatou-se que o paciente já estava em um 
período de proservação médica e sob tratamento nutricional. Dessa forma, foi possível realizar a terapia para remoção das pigmentações enegrecidas da superfície dentária; entretanto, como manchas extrínsecas estavam menores e menos pigmentadas, foi possível a realização do tratamento em uma única sessão.

Para tanto, foi realizada uma profilaxia com Pasta Profilática Herjos Tutti-Frutti (COLTENEE - BRASIL) com Pedra Pomes Asfer (BRASIL) para remoção das manchas enegrecidas com coloração mais intensa, além da utilização do jato de bicarbonato e curetas de Gracey para remoção das pigmentações nas áreas de difícil acesso. Após isso, observou-se uma excelente remoção das manchas nas superfícies dentárias (Figura 4).

Figura 4 - Resultado do tratamento de sessão única para remoção das pigmentações dentárias por sulfato ferroso.

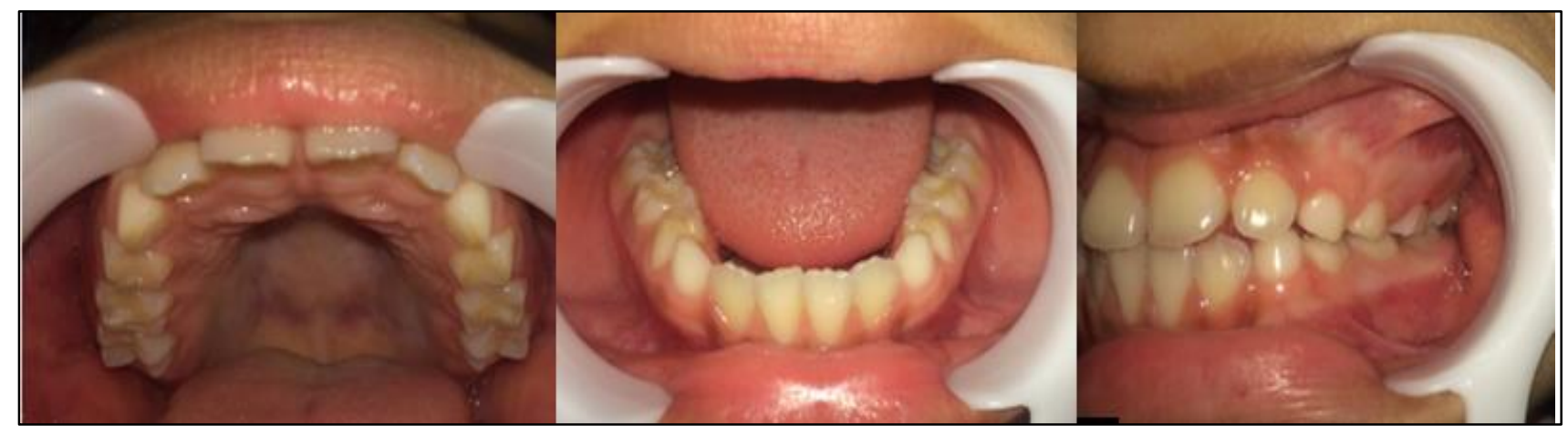

Fonte: Dados do trabalho, 2019.

\section{DISCUSSÃO}

A anemia atinge hoje cerca de um terço da população mundial, sendo um dos distúrbios fisiológicos de maior prevalência. Se não tratada, a anemia pode trazer consequências sérias como alterações no desenvolvimento físico, comportamental, alterações gastrointestinais, na pele e sistema imunológico. (GARCIA LFM, et al., 2016).

Nesse sentido, a anemia ferropriva ocorre quando há a privação/redução do mineral ferro, o qual é importante para a síntese de hemácias no sangue e transporte de oxigênio; logo, quando há restrição desse elemento, também ocorre a diminuição da hemoglobina transportada no sangue, ocasionado vários fatores adversos (YAMAGISHI JA, et al., 2017).

Um dos tratamentos mais difundidos para a anemia ferropriva é a de reposição de ferro por meio de medicamentos. Como no caso descrito, o referido paciente realizou suplementações medicamentosas com sulfato ferroso por via oral, nas duas ocasiões em que ele e apresentou um quadro de anemia ferropriva. Desse modo, a via oral caracteriza-se como melhor opção para a reposição férrica, método esse ratificado pela comunidade científica, posto que apresenta melhor eficácia terapêutica, menor risco de toxicidade medicamentosa, melhor aceitação gastrointestinal, baixa incidência de eventos adversos e número de tomadas diárias necessárias aceitável (CANÇADO RD, et al., 2010).

Sabe-se que as pigmentações negras do esmalte se devem à coloração extrínseca e estão associadas com problemas estéticos (BRANCO CMCC, et al., 2016). Essas intercorrências na aparência do sorriso podem interferir diretamente no bem-estar do paciente envolvido, como no caso descrito, o paciente e seu responsável apresentavam grande desconforto diante das pigmentações enegrecidas nas superfícies dentárias e por isso procuraram atendimento odontológico. Diante disso, verificou-se na literatura que uso contínuo de sulfato ferroso por via oral para tratamento complementar da anemia ferropriva, pode ter como 
consequência adversa o surgimento de pigmentações extrínsecas enegrecidas nas superfícies do esmalte dentário (MATHIAS MF, et al., 2008).

Essas pigmentações enegrecidas caracterizam-se como um tipo específico de descoloração externa observado em $2,4-21 \%$ de todas as crianças, na região de vestíbulo e nas superfícies linguais ao longo da margem gengival, firmemente presa às superfícies dos dentes, formadas pelo sulfeto férrico formado pela reação do hidrogênio da ação bacteriana e o ferro presente na saliva ou no sulco gengival, dando assim origem a essas pigmentações enegrecidas (RACHID F e MEHDI HE, 2016).

Essa constatação da literatura tem correlação com o caso uma vez que o paciente apresentou manchas enegrecidas em nível de esmalte dentário na palatina dos dentes 11,12,21; na área cervical da palatina dos dentes $55,16,65,26,31,41,42$ e na área cervical vestibular dos dentes 55,16,36. E após 4 meses também apresentou pigmentações nas superfícies palatinas dos dentes 16, 55, 65, 26, 36, 31,32, 41, 42, 46 e no vestibular dos dentes 16,85 e 46.

Como essas manchas são extremamente aderidas ao esmalte dentário, a intervenção do profissional fazse necessária para remoção desses pigmentos. Desse modo, o planejamento de tratamento traçado para o paciente foi dividido em duas etapas, sendo que na primeira realizou-se uma profilaxia, com pasta profilática, pedra pomes e aplicação de flúor, sendo esse método difundido pela comunidade científica (SABA C, et al., 2006).

Entretanto, como não houve o desparecimento completo das manchas enegrecidas, utilizou-se, em outra sessão, outra forma de remoção de manchas, através da profilaxia e polimento coronário com o jato de bicarbonato de sódio e raspagem supra gengival, método esse também ratificado no campo científico (GASPARETTO A, et al., 2003)

Vale ressaltar que a remoção dos pigmentos enegrecidos deve ser realizada após o término do tratamento médico, somado a isso, a sua realização deve ser avaliada de maneira individualizada, não devendo usar aparelhos ultrassônicos pela capacidade de desgastar o esmalte dentário (SABA C, et al., 2006). Desse modo, quando o paciente retornou para realizar a proservação, não foi possível realizar o tratamento para remoção das manchas enegrecidas, uma vez que, o mesmo ainda não havia terminado o seu tratamento médico com suplementação férrica; logo não há indicação para o mesmo.

Estudos revelam que esse tipo de pigmentação ocorre com mais frequência da dentadura decídua, mas também ocorre na dentadura mista. Somado a isso, foi constatado, a ocorrência de recidivas após a remoção das respectivas manchas enegrecidas, fato esse observado após o retorno do paciente em questão (MOURA AL, et al., 2013).

Por outro lado, autores observaram que na dentadura permanente não foi detectada esse tipo de pigmentação, visto que alguns patógenos que colonizam a cavidade bucal e estão envolvidos nas manchas enegrecidas, apesar de serem oportunistas e coexistirem de maneira harmônica, estão presentes apenas em algumas fases da vida, fato esse que pode explicar a pigmentação por sulfato ferroso na dentadura mista e decídua (BANDON D, et al., 2011).

Logo, não só se verifica a importância de um bom exame clínico; mas também de um bom plano de tratamento e proservação do paciente para averiguar a evolução das machas extrínsecas enegrecidas no esmalte dentário.

\section{CONSIDERAÇÕES FINAIS}

Como no caso clínico exposto, foi possível observar pigmentações dentárias ocasionadas pela administração medicamentosa de sulfato ferroso, que acometem a dentadura decídua e mista; provocando então manchas enegrecidas extrínsecas nas superfícies do esmalte dentário. Logo, indica-se a remoção dessas manchas tanto para o não comprometimento do periodonto marginal, quanto para não implicação na estética. 


\section{REFERÊNCIAS}

1. AMARAL SM, et al. Reações medicamentosas na cavidade oral: aspectos relevantes na Estomatologia. Revista Brasileira de Odontologia, 2009; 66(1):41.

2. BANDON D, et al. Exogenous tooth discoloration in children: black stains. Arch Pediatr, 2011; 18(12): 1348-52

3. BRANCO CMCC, et al. Pigmentações extrínsecas negras do esmalte em Odontopediatria. Revista Cubana de Estomatol, 2016; 53(3):153-161.

4. CAMASCHELLA C. Iron-Deficiency Anemia. New England Journal of Medicine, 2015; 372(19): 1832-1843.

5. CANCADO RD, et al. Tratamento da anemia ferropriva com ferro por via oral. Rev. Bras. Hematol. Hemoter, 2010; 32(suppl. 2):114-120.

6. COSTA MT, et al. Biofilms of black tooth stains: PCR analysis reveals presence of Streptococcus mutans. Braz Dent J, 2012; 23(5): 555-8.

7. GARCIA LFM, et al. Prevalência de anemia em crianças de 0 a 12 anos em uma unidade de pronto atendimento em Santa Maria-RS. Disciplinarum Scientia| Saúde, 2016; 12(1):1-10.

8. GASPARETTO A, et al. Prevalence of black tooth stains and dental caries in Brazilian schoolchildren. Braz Dent J, $2003 ; 14(3): 157-61$.

9. HEINRICH-WELTZIEN R, et al. Dental caries and microbiota in children with black stain and non-discoloured dental plaque. Caries Res. 2014; 48(2): 118-25.

10. LANGSTAFF RJ. Tratamiento de deficiencia de anemia. Medicina, 2014; 3(4): 191-198.

11. MARTIN JMG, et al. Prevalence of black stain and associated risk factors in preschool Spanish children. Pediatr Int, 2013; 55(3):355-9.

12. MATHIAS MF, et al. Anemia ferropriva e pigmentação dentária por sulfato ferroso: revisão de literatura e relato de casos clínicos. Rev Bras Pesq Saúde, 2008;10(1):57-61.

13. MOURA AL, et al. Manchas extrínsecas negras - relato de caso clínico. Revista da Faculdade de Odontologia de Lins, 2013; 23(1): 59-64.

14. RACHID F, MEHDI HE. Black Stains in Primary Teeth: Overview. Pediatr Dent Care, 2016; 1(123): 2.

15. SABA C, et al. Black stains in the mixed dentition: a PCR micro-biological study of the etiopathogenic bacteria. J Clin Pediatric Dent, 2006; 30: 219-224.

16. SILVA EM. MANCHAS EXTRÍNSECAS NEGRAS E MARRONS EM CRIANÇAS. Trabalho de Conclusão de Curso (Curso de Odontologia). Faculdade São Lucas, Porto Velho, 2016.

17. SOUKOS NS, et al. Phototargeting oral black-pigmented bacteria. Antimicrob Agents Chemother, 2005; 49(4):13916.

18. WORLD HEALTH ORGANIZATION. The Global Prevalence of Anaemia in 2011. Geneva: World Health Organization; 2015.

19. YAMAGISHI JA, et al. Anemia ferropriva. Revista Científica da Faculdade de Educação e Meio Ambiente, 2017; 8(1):99-110.

20. ZHANG F, et al. A preliminary study on the relationship between iron and black extrinsic tooth stain in children. Lett Appl Microbiol, 2017; 64(6): 424-429. 